
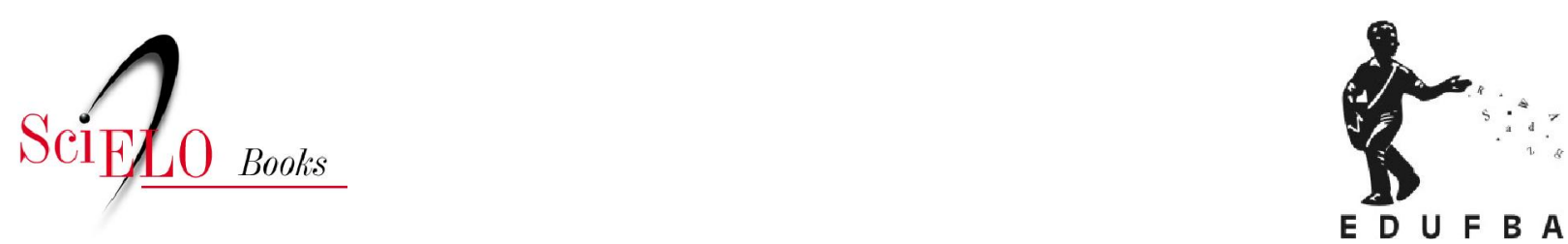

\title{
Mecanismos para a construção da transparência uma breve análise do caminho entre a democracia representativa e a democracia digital
}

\author{
Ana Cláudia Farranha
}

\section{SciELO Books / SciELO Livros / SciELO Libros}

FARRANHA, A.C. Mecanismos para a construção da transparência: uma breve análise do caminho entre a democracia representativa e a democracia digital. In: PINHO, J.A.G., ed. Artefatos digitais para mobilização da sociedade civil: perspectivas para avanço da democracia [online]. Salvador: EDUFBA, 2016, pp. 17-35. ISBN: 978-85-232-1877-5. https://doi.org/10.7476/9788523218775.0003.

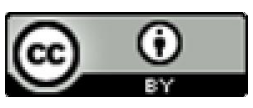

All the contents of this work, except where otherwise noted, is licensed under a Creative Commons Attribution $\underline{4.0 \text { International license. }}$

Todo o conteúdo deste trabalho, exceto quando houver ressalva, é publicado sob a licença Creative Commons Atribição 4.0.

Todo el contenido de esta obra, excepto donde se indique lo contrario, está bajo licencia de la licencia Creative Commons Reconocimento 4.0. 


\section{MECANISMOS PARA A CONSTRUÇÃO DA TRANSPARÊNCIA}

uma breve análise do caminho entre a democracia representativa e a democracia digital ${ }^{1}$

ANA CLÁUDIA FARRANHA

\section{INTRODUÇÃO}

As promessas não cumpridas da democracia - essa é uma frase que está presente em um dos livros muito conhecidos na Ciência Política, O Futuro da Democracia, de Norberto Bobbio. Nesse livro, o autor problematiza o tema enfatizando o porquê de a democracia ainda não ter sido completamente realizada no Estado Moderno. Assim, caminhos alternativos poderiam ser pensados como forma de realizar as promessas democráticas. A possibilidade de utilização de mecanismos mais diretos, combinados com a representação, segundo o autor, poderia ser uma saída para o impasse em questão. (BOBBIO, 1986, p. 52)

Passados 30 anos da primeira edição da obra (1984), tais promessas expressam a lógica de um formato de exercício de poder baseado na igualdade de procedimentos e condição ainda inconclusos. E, junto ao

1 Esse texto foi originalmente apresentado no VI Congresso CONSAD de Gestão Pública, ocorrido em Brasília, em 2013. 
não cumprimento dessas promessas, outros desafios se colocam diante do exercício do poder: a ampliação da transparência, a informação ao cidadão, a necessidade de decisões que envolvam maior compromisso de todos os participantes e a prestação de serviços de qualidade como forma, também, de efetivação de uma lógica de democracia, capaz de ampliar o controle sobre a ação do agente púbico e a participação do cidadão nos processos decisórios.

Partindo dessa perspectiva, o presente texto procura analisar, de maneira ainda exploratória, em que medida formatos de interação baseados na internet (web 2.0 e outros mecanismos) podem auxiliar no cumprimento tais promessas.

Em outras palavras, trata-se de tentar responder às questões propostas por Bobbio, considerando os novos formatos de interação com o cidadão. Para tanto, serão retomadas, brevemente, algumas considerações sobre a democracia direta, destacando as possibilidades que tal formato coloca para as questões da transparência e participação na atualidade.

$\mathrm{Na}$ sequência, apresentam-se elementos constitutivos da democracia on-line, discorrendo sobre o papel das redes sociais (Facebook e Twitter) e, por fim, identificam-se alguns dos desafios colocados para a Administração Pública nesse contexto. Como forma de balizar algumas das discussões propostas, as ideias contidas nele baseiam-se em resultados preliminares da pesquisa "A Administração Pública nas redes sociais: discutindo elementos acerca das novas formas de informação ao cidadão"(CNPq/UnB).

\section{UMA BREVE LEITURA DO CONCEITO DE DEMOCRACIA}

Buscar uma definição de democracia não é tarefa muito fácil diante da multiplicidade de formulações feitas em torno do conceito. Nesse sentido, esse capítulo escolheu trabalhar com a formulação rousseaniana, tendo em vista que ela ajuda a problematizar o tema proposto: ampliação da transparência e a participação e, ao mesmo tempo, retoma alguns conceitos, os quais influenciarão fortemente nos contornos 
da democracia contemporânea. Em outras palavras, é em Rousseau que identificamos os fundamentos da democracia direta, os quais, nos tempos atuais, ganham o contorno de democracia participativa.

A definição de democracia que Rousseau nos apresenta é a forma de governo na qual o povo tem o poder de legislar. Ao mesmo tempo, o povo assume o papel de executar as leis, pois se a vontade geral prevalece o povo estará submetido a si mesmo, conforme os requisitos estabelecidos para o pacto social. Por isso, inicialmente, a forma de democracia a que Rousseau adere é a democracia direta, visto que a vontade geral não pode ser representada: cabe, exclusivamente, ao povo a decisão sobre os assuntos da sociedade.

A aristocracia e a monarquia não permitem a participação direta do povo no processo político, pois, como o autor escreve, a primeira limita o poder político nas mãos de uma pequena parte da sociedade e a segunda concentra o poder de legislar, exclusivamente, nas mãos do monarca, de forma que nesses formatos de governo a vontade geral seria suprimida.

O governo, nessa abordagem, deveria ser apenas um "empregado" do povo, e todos os seus atos deveriam estar totalmente condicionados à aprovação da assembleia popular como forma de colocar a vontade geral acima das vontades particulares. A ideia de democracia direta defendida pelo autor resgata a democracia grega, trazendo a ideia do espaço público, ${ }^{2}$ de uma arena de debate ampla, que acolhe os interesses de toda a sociedade, isto é, ressalta a vontade geral como princípio norteador da vida política e social.

A democracia que Rousseau propõe, ou seja, aquela que coloca a vontade geral e a soberania popular acima dos interesses particulares, a que requer a constante aprovação do povo nas questões que regulamentariam a vida política e que não admite a representação da vontade

2 Nesse trabalho não será desenvolvida uma concepção mais esboçada de espaço público, mas trata-se de um conceito útil para a discussão proposta tendo em vista que o uso dele extrapola uma visão formalista da democracia, inserindo o debate democrático em uma vertente mais culturalista e capaz de engendrar novas práticas no exercício do poder político. Sobre isso, ver Arendt (1993), Fraser (1993) e Habermas (1987). 
geral, é a democracia direta. Ela dependeria de situações nas quais a igualdade não é só um procedimento formal, mas uma racionalidade capaz de dar ao "povo" (ou a todos) a condição de se autorrepresentar. (ROUSSEAU, 1973, p. 15) De alguma forma, atributos como o ser visto e ouvido e a autonomia da expressão subjazem a essa formulação.

Por outro lado, o autor estabelece rígidas críticas sobre a democracia representativa. Para Rousseau, esse modelo de governo não representa a vontade geral, mas a vontade de particulares pelo fato de instituir um parlamento que apenas acolhe os conflitos das diversas classes sociais. É um sistema que abre a esfera política para o conflito de interesses ao invés de concretizar a vontade popular, o que configura a alienação da vontade geral: o governo, que deveria ser um comissário do povo, passa a ser o titular da vontade geral.

Nada é mais perigoso que a influência dos interesses privados nos negócios públicos; e o abuso das leis por parte do governo constitui um mal menor que a corrupção por parte do legislador, continuação infalível dos alvos particulares. Então, alterado o Estado em sua substância, toda reforma se torna impossível. (ROUSSEAU, 1973, p. 73)

Essas formulações conduzem as conclusões a dois pontos. Primeiro, a proposta de democracia em Rousseau não se limita a uma forma de governo, mas vai além da esfera institucional, colocando-se como uma concepção de vida de caráter moral ao considerar o bem-comum superior ao benefício individual; a democracia deve ser entendida como um valor moral a ser universalizado na sociedade. E um segundo, que interessa a esse texto, a necessidade de que esse governo - titular de uma vontade geral - seja constantemente fiscalizado e acompanhado. O próprio Rousseau desacredita nessa possibilidade. ${ }^{3}$ Entretanto, para os dilemas contemporâneos da democracia, a lógica da vigilância e do

3 Há várias passagens do contrato social em que o autor afirma que a democracia, nesse formato, deveria se utilizada "se houvesse um povo de deuses". Entretanto, para os dilemas contemporâneos da democracia, a lógica da vigilância e do debate constante voltado para a construção da vontade geral (consenso) parece ser pertinente. 
debate constante voltado para a construção da vontade geral (consenso) parece ser pertinente.

Abrindo um lapso temporal entre a teoria política e as questões levantadas por Bobbio sobre o futuro da democracia, mencionadas no início desse texto, retoma-se alguns aspectos do debate sobre transparência. Assim, a partir das considerações de Rousseau, observa-se que o problema colocado para a efetivação da democracia refere-se ao controle, seja ele articulado do ponto de vista político (sobre a forma como se formam as posições) ou o administrativo (sobre a forma como se fiscaliza a ação do governo).

Nesse aspecto, o tema referente ao uso de novas Tecnologias da Informação e Comunicação (TICs) parece pertinente como propulsor de uma inovação do conceito de democracia. Para tanto, somase ao debate o conceito de accountability. Prado, Ribeiro e Diniz (2012, p. 16), discutindo as relações entre tecnologia, informação e democracia, apresentam a seguinte perspectiva para termo:

O debate teórico surgido nos últimos nos sobre accountabilitty está relacionado ao fato de as discussões sobre os conceitos terem sido colocadas na agenda pública em meado dos anos 1990, no contexto da segunda geração de reformas do Estado. Apesar do termo accountabilitty ser relativamente freqüente no debate internacional dos últimos anos, o termo não está precisamente definido na literatura $[\ldots]$.

Os autores continuam destacando que a Organização das Nações Unidas (ONU) define o termo como "agir com responsabilidade e de forma responsiva”. (PRADO; RIBEIRO; DINIZ, p. 16) Assim, apontam, com base nas terminologias adotadas pela United Nations Public Administration Network (UNPAN), aspectos da dimensão interna e externa do termo, as quais podem ser caracterizadas, no quadro 1, conforme segue: 
Quadro 1 - Dimensões da accountability

\begin{tabular}{|c|c|}
\hline DIMENSÃO & CARACTERÍSTICAS \\
\hline Interna & $\begin{array}{l}\text { Essa dimensão é caracterizada pelas ações/decisões dos agentes } \\
\text { (servidores) nas esferas gerencial, legal, profissional, política e } \\
\text { financeira que afetam a totalidade da organização. Essas ações } \\
\text { definições têm repercussões externas e podem, também, ser alvo } \\
\text { de interface dos servidores com outras esferas do poder público. }\end{array}$ \\
\hline Externa & $\begin{array}{l}\text { Refere-se àquele controle exercido "por fora". } \\
\text { Trata-se da repercussão da ação interna nas diferentes esferas para } \\
\text { as quais ela é dirigida. Accountability política, ligando o servidor às } \\
\text { esferas de legitimação da política (Poder Legislativo); accountability } \\
\text { legal, relativa à ação ligada ao sistema legal, obediências aos } \\
\text { procedimentos normativos (Poder Judiciário); a accountability } \\
\text { financeira, relacionada aos processos de financiamento e, } \\
\text { accountability pública, relacionada aos cidadãos em geral. }\end{array}$ \\
\hline
\end{tabular}

Fonte: elaborado pela autora com base em Prado, Ribeiro e Diniz (2012) e Heeks (1998). ${ }^{4}$

Essa caracterização é importante para a análise proposta, pois ela possibilita compreender em que medida o tema da democracia direta se recoloca no espaço da Administração Pública, como ele está ligado à perspectiva do controle, principalmente, o controle externo das ações dos servidores e, como a possibilidade de efetivar essas promessas não cumpridas da democracia, de alguma forma, estão presentes no uso de tecnologias da informação como mecanismos que se propõem à maior eficácia e efetividade, capazes de ampliar a participação do cidadão. Sob essa perspectiva, uma questão a ser levantada é: seria a democracia on-line um caminho possível? Essa é a discussão do próximo item.

\section{DEMOCRACIA ON-LINE: POSSIBILIDADES DE UM ESPAÇO DE MAIOR PARTICIPAÇÃO ?}

Se a lógica proposta por Rousseau é de uma democracia direta, viva e motivada pela participação do cidadão, ainda que ao longo de suas formulações ele mesmo desacredite dessa existência, o desenvolvimento do estado democrático mostrou-se mais afinado com uma perspectiva que incentiva a técnica nos processos decisórios (daí a expressão "promessas não cumpridas”).

4 Para uma compreensão mais detalhada dessa discussão, recomenda-se um exame dos textos citados, pois eles contêm uma figura que define com mais exatidão a discussão proposta. 
Entretanto, os anos 1990, caracterizados como os anos da Reforma do Estado, trazem um conjunto de novos procedimentos, dentre os quais a possibilidade do uso da internet como forma de garantir maior acesso ao cidadão, divulgação da informação, desburocratização dos serviços e, em alguma medida, a intenção de construir mecanismos de consulta e participação, os quais deveriam proporcionar maior interação, controle, atuação e debate público constituindo um formato de democracia que vem sendo chamado de "democracia digital".

Muitos são os trabalhos que discutem esse conceito. (DAHLBERG, 2005; DI MAGGIO et al. 2001; HAMLETT, 2003; MOSCO; FOSTER, 2001) Para esse trabalho, escolheu-se a abordagem trazida por Echavarría (2012, p. 69, tradução nossa), a autora aponta que trata-se de uma "complementação da democracia representativa, tomando como base o uso de mecanismos de participação, com poder de decisão e controle da ação pública, mediados pelo tecnologia da informação." Entretanto, a autora adverte que "qualquer outra oportunidade de interação articulada pelas TICs, cujo vínculo se estabeleça entre os cidadãos com a gestão deveria ser considerada 'somente' governo eletrônico." 5

A discussão proposta pela autora segue destacando as diferenças entre os serviços voltados para gestão e aqueles dirigidos à decisão política. Assim, afirma:

A 'àgora eletrônica' se define como o âmbito da participação política que, de maneira inicialmente, complementar e potencialmente transformadora dos espaços tradicionais de participação, seria definida pelos espaços deliberativos criados e/ ou articulados com a incorporação das TICs. ${ }^{6}$ (ECHAVARRÍA, 2012, p. 69)

5 "Consideramos que el desarrollo de la "democracia electrónica" o digital se refiere, en principio, a una complemntación de la democracia representativa a través de la inclusión tecnológica de mecanismos participativos con poder de decisión de la ciudadanía y de control efectivo sobre la acción pública. Adviertiendo que cualquier otra oportunidad de interacción mediada por las TIC en el vínculo de los ciudadanos con la géstion pública debería ser considerada ‘solamente' gobierno electrónico.” (ECHAVARRÍA, 2012, p. 69)

6 El 'ágora eletrónica' se define como el ambito de la participación política que, de manera inicialmente complementaria y potencialmente transformadora de los espacios tradicionales 
Esse fragmento demonstra duas perspectivas em torno da democracia on-line. Uma que a autora considera complementar à democracia representativa e capaz de ampliar a possibilidade de informação do cidadão e, outra, considerada forte (fuerte), articulando mais amplamente o potencial transformador das TICs para as instituições democráticas. Buscando reproduzir essas ideias, apresenta-se o quadro abaixo.

Quadro 2 - Visões sobre a democracia on-line

\begin{tabular}{|ll|}
\hline Perspectiva & Enfatiza a dinamização e flexibilização das formas de \\
complementar(débil) & representação política, destacando maior aproximação entre \\
& representantes e representados, por meio das tecnologias da \\
& informação. Assim, a democracia seria mais que um método \\
& de seleção e autorização de "representantes fiduciários", \\
& isto é, aproximando os eleitores através da circulação de \\
& informação sobre os processos de tomada de decisão \\
& (por exemplo, transmissão completa dos debate nas casas \\
& legislativas) e aumentando, consequentemente, os momentos \\
& de prestação de contas (responsabilização) dos representantes \\
& na generalização da informação e não somente nos \\
& momentos eleitorais. Nessa visão, os eleitores se tornam mais \\
& autônomos, uma vez que há uma multiplicação dos fluxos \\
& de comunicação, possibilitando aos cidadãos ativos - que \\
& buscam informação - mais acesso às opiniões encontradas e \\
& que se manifestam nos distintos meios de comunicação. \\
Essa visão potencializa a capacidade transformadora da & tecnologia ao afirmar que ela maximiza e oportuniza a \\
comunicação política ao libertá-la da medicação (tradicional da \\
democracia representativa). Essa perspectiva considera que a \\
tecnologia oferece uma oportunidade para a "operatividade" \\
do poder democrático, tanto em termos agregativos como \\
deliberativos. Isto é, permitiria a integração da titularidade \\
e exercício do poder parte dos cidadãos, em formatos que \\
reforçam a presença imediata da cidadania em todas as esferas \\
da vida pública (voto eletrônico, sondagens instantâneas \\
sobre temas da cidadania) ou em desenhos que procuram \\
a concretização de um debate público vinculante (foros, \\
comunidades virtuais, etc.) \\
\hline forte
\end{tabular}

Fonte: Echavarria (2012, p. 70).

Essas visões não esgotam as discussões sobre o sentido de democracia on-line, mas mostram que há diferentes formas de promover

de participación, quedaria definido por los espacios deliberativos creados y/ o apoyados com la incorporación de las TIC's. (ECHAVARRÍA, 2012, p. 69) 
maior acesso do cidadão à informação, ao debate público e a formas de escolha e decisão política, mediadas pela tecnologia. Entretanto, que tipos de procedimentos, voltados à transparência, essas experiências colocam? É a democracia on-line um espaço para aprofundamento das questões públicas? Ainda que não seja objetivo desse artigo responder a essas questões, pode-se mencionar algumas experiências acerca desse formato. São elas:

I. Gabinete Digital: Trata-se de uma experiência desenvolvida pelo Governo do Rio Grande do Sul, criada em 2011, com objetivo de incorporar novas ferramentas de participação, oferecendo diferentes oportunidades ao cidadão de influenciar a gestão pública e exercer maior controle social sob o Estado. (RIO GRANDE DO SUL, 2013) Sua criação pautou-se em exemplos de democracia digital do Brasil e do exterior.

2. Orçamento Participativo Digital (Prefeitura de Belo Horizonte): Criado em 2006, com objetivo de ampliar a participação dos cidadãos no processo de deliberação do Orçamento Participativo Municipal, priorizando a escolha de investimentos. Naquele ano, foram escolhidas nove obras que seriam prioritárias. Essa escolha se deu pela internet, tendo a participação de 172.938 eleitores, cujos votos somaram 503 mil. ${ }^{7}$

3. E-democracia - Câmara dos Deputados: Trata-se de uma iniciativa desenvolvida no âmbito da Câmara dos Deputados, cuja proposta é, por meio da internet, incentivar a participação da sociedade no debate de temas importantes para o país. Para tanto, há dois tipos de participação: as comunidades legislativas e o espaço livre. Nas comunidades, a discussão volta-se para temas referentes a projetos de lei já existentes, oferecendo não somente o espaço de discussão, mas trazendo a perspectiva de informar ao cidadão a respeito do andamento da matéria no Congresso Nacional. O espaço livre funciona como uma tribuna, onde temas podem ser pautados e virem a se-tornar objetos das comunidades legislativas. (BRASIL, 2013)

7 Sobre isso ver Sampaio e colaboradores (2010) e Belo Horizonte (2008). 
Há uma série de outros exemplos (cidades digitais, fóruns de discussão, etc.), que poderiam ser citados, entretanto a menção a essas experiências ajuda a compreender as diferentes possibilidades em torno da democracia on-line, e, principalmente, remete a construção de um espaço de discussão e debate, que pode não levar, necessariamente, à tomada de decisões mais partilhadas, mas traz para o lugar público, aspectos que norteiam as questões políticas da sociedade brasileira.

A esses espaços adiciona-se a existência de fanpages e comunidades de órgãos da Administração Pública nas redes sociais, principalmente, Facebook e Twitter. Importante informar que existente basicamente três formatos de interação no Facebook: os perfis, cujo objetivo é estabelecer a interface entre usuários comuns, sendo utilizado por pessoas e não por organizações. A fanpage destina-se a organizações, pois vai mais além do perfil pessoal, destinado a amizades e estabelecendo relacionamentos que promovem a organização, informam sobre suas ações e criam um espaço de fidelização para seus "fans". As comunidades são grupos de discussão constituídos por usuários interessados em temas e debates específicos.

No caso da Administração Pública Federal, primeiramente foram estabelecidos perfis e, mais recentemente tais perfis foram transformados em fanpages. Conforme levantamento feito em fevereiro de 2013 , existem 18 fanpages de Ministérios do Governo Federal, cujo interesse em compreendê-los é identificar em que medida a presença destes órgãos auxilia no processo de transparência das ações públicas - cumprindo algumas das promessas da democracia.

Um aspecto importante dessa compreensão é retomar o conceito de rede, desenvolvido a partir de uma análise da teoria social, destacando as características e potenciais desse formato.

REDES SOCIAIS, DEMOCRACIA E TRANSPARÊNCIA:

PROBLEMAS E QUESTÕES ANALÍTICAS

A noção de rede está presente na discussão proposta por Castells (1999). Analisando o crescimento das novas formas de interação social, mediadas pela perspectiva da revolução informacional, o autor destaca que a 
metáfora da rede insinua uma situação na qual as interconexões se dão em nós, através dos quais vários cabos se ligam.

Nas redes sociais, organizacionais ou interpessoais estabelecem-se canais de relações entre diferentes elementos. Tais redes podem ser definidas, primeiramente, pela natureza de seus elementos (pessoas, organizações, etc.), pela natureza dos canais de conexão; e pela natureza das transações que ocorrem nesses canais. Em segundo lugar, as redes podem ser caracterizadas pelo seu alcance, complexidade, estabilidade, grau de homogeneidade e flexibilidade. Isso levaria a novas possibilidades de interação entre Estado e sociedade civil, cabendo a esta uma parcela, cada vez maior, de responsabilidade, seja no que se refere à elaboração e concepção das políticas, ou de sua gestão.

Assim, a informação se constitui em um importante instrumento de poder e de operacionalização dos canais desse Estado. Castells (1999, v. 1, p. 498) destaca que

Redes são estruturas abertas capazes de expandir de forma ilimitada, integrando novos nós desde que consigam comunicar-se dentro da rede, ou seja, desde que consigam compartilhar os mesmos códigos de comunicação (por exemplo, valores ou objetivos de desempenho). Uma estrutura social com base em redes é um sistema aberto altamente dinâmico suscetível de inovação sem ameaças ao seu equilíbrio. Redes são instrumentos apropriados para a economia capitalista baseada na inovação, globalização e concentração descentralizada; para o trabalho, trabalhadores e empresas voltadas para a flexibilidade e adaptabilidade para uma cultura de desconstrução e reconstrução contínua; para uma política destinada ao processamento instantâneo de novos valores humanos públicos; e para uma organização social que vise a suplantação do espaço e invalidação do tempo.

Observa-se que as redes trazem para a discussão da teoria social um novo formato de relações e interações econômicas, políticas e sociais, possibilitando maior descentralização, flexibilidade - e quem sabe - democracia. 
Buscando desnaturalizar o sentido do referido conceito e, em alguma perspectiva, divergido de Castells, Acioli (2007, p. 2) concorda que o sentido de rede envolve dinamicidade e rearranja elementos do tecido social. Destaca, assim, a seguinte perspectiva do conceito:

O termo rede sugere ainda fluxo, movimento, indicando uma aproximação com as mais variadas áreas de conhecimento conforme apontamos inicialmente. Em Ciências Sociais, rede seria o conjunto de relações sociais entre um conjunto de atores e também entre os próprios atores. Designa, ainda, os movimentos pouco institucionalizados, reunindo indivíduos ou grupos numa associação cujos limites são variáveis e sujeitos a reinterpretações. ${ }^{8}$

Entretanto, ao mesmo tempo em que a literatura aponta, nas redes, aspectos inovadores e de releitura da sociedade contemporânea, problematiza-se os resultados dessa interação. E, em particular, o Estado - nação, que na sua construção e articulação de poder passa a ser apontado como um caso de contradições resultantes da sociedade em rede. Castells, analisa os aspectos que se referem à crise do Estado-nação e as possibilidades que se colocam para sua ação, num momento em que este parece estar destituído de poder. Sua tese central é a de que, no contexto atual, há

A tentativa de o Estado reafirmar seu poder na arena global pelo desenvolvimento de instituições supranacionais acaba comprometendo ainda mais sua soberania. E os esforços do Estado para restaurar sua legitimidade por meio da descentralização do poder administrativo, delegando-o às esferas regionais e locais, estimulam as tendências centrífugas ao trazer os cidadãos para a órbita do governo, aumentando, porém a indiferença em relação ao Estado-Nação. (CASTELLS, 1999, v. 2, p. 287)

Os elementos de que parte Castells estão relacionados com o fato de que o contexto atual é marcado por um processo de globalização, de

8 As ideias apresentadas pela autora baseiam-se no argumento de Colonous (1995). 
uma economia que tende a se estruturar a partir de um elevado grau de interdependência, o que lhe confere um caráter de rede. E a questão que nos coloca é: como a possibilidade de funcionamento em rede pode ser verificada no Estado-nação? Seu argumento é que, embora o Estado-nação tenha perdido seu poder no que se refere à regulação econômica, na verdade, ele continua a deter certo poderio no que se refere à regulação das políticas sociais, ao mesmo tempo, mostra como as empresas que agem transnacionalmente vão se colocar numa posição de defesa em relação aos benefícios e a legislação social vigente em muitos destes países. (CASTELLS, 1999, v. 1)

O autor identifica um conjunto de ações deste Estado, no sentido de descentralizar o poder e reparti-lo com agências locais e regionais de elaboração de políticas públicas. Entretanto, para Castells esta perspectiva assinala elementos acerca de uma crise de legitimidade deste Estadoque, ao mesmo tempo em que delega poderes, não é capaz de se articular a partir desta delegação. Em outras palavras, embora o modelo se volte para aspectos da descentralização, o resultado dele é absolutamente imprevisível, o que leva o autor a afirmar que

Para superar tal crise de legitimação, os Estados descentralizam parte de seu poder em favor de instituições políticas locais e regionais. Essa transferência de poder decorre de duas tendências convergentes. De um lado, dada a diferenciação territorial entre as instituições do Estado, as identidades das minorias regionais e nacionais conseguem se manifestar com maior desenvoltura em níveis local e regional. Por outro lado, os governos nacionais tendem a concentrar-se na administração dos desafios impostos pela globalização da riqueza, da comunicação e do poder, permitindo, portanto que escalões inferiores do governo assumam a responsabilidade pelas relações com a sociedade tratando das questões do dia-a-dia, com o objetivo de reconstruir sua legitimidade por meio da descentralização do poder. Contudo, uma vez instaurado tal processo de descentralização, os governos locais e regionais podem tomar iniciativas em nome de suas respectivas populações, e até mesmo elaborar estratégias de desenvolvimento distintas do sistema global, o 
que faz com que concorram diretamente com seus próprios Estados centrais. (CASTELLS, 1999, v. 1, p. 319)

Acioli (2007) chama a atenção para fragmentação existente em um mundo articulado a partir de redes, e alerta para a necessidade de que o global e local sejam rearticulados em uma nova produção de sentido. Destaca que

Podemos, portanto pensar que nesse mundo em redes, onde há mais quantidade do que qualidade de informação, a possibilidade de fragmentação de saberes e culturas, e, portanto de sujeitos é muito grande Nesse sentido, o entrelaçamento entre o local e o global torna-se uma reorganização do tempo e do espaço que pode como diria Giddens, dissolver o sujeito num mundo de signos sem centro. Daí a necessidade de pensar o local e o global de modo articulado, com também as várias formas de valorização dos espaços internos - entendidos como os espaços locais. (ACIOLI, 2007, p. 10-11)

Considerando as discussões desenvolvidas até esse ponto, a perspectiva de que a rede descentraliza e ao mesmo tempo fragmenta, colocando como desafio uma nova articulação do Estado desde a perspectiva global até o nível local, é útil para compreender o sentido da informação existente nas fanpages dos Ministérios, pois auxilia a pensar qual perspectiva se coloca a partir dessa ação. Questiona-se, assim, se não se trata de um novo formato de interação com o cidadão, proporcionando mais transparência, publicidade e democracia na gestão desse Estado

\section{Papel de Facebook e Twitter nesse contexto}

As mudanças na gestão do Estado resultantes do processo de reformas dos anos 1990 trouxeram como uma das ferramentas centrais o uso da internet. Esse processo segue diferentes fases e chega à primeira década dos anos 2000, agregando um tipo de ferramenta denominado Web 2.0, a qual designa uma segunda geração de comunidades e serviços baseados na plataforma Web, como wikis e aplicações baseadas em redes sociais. Embora o termo tenha uma conotação de uma nova 
versão para a web, ele não se refere à atualização nas suas especificações técnicas, mas a uma mudança na forma como ela é encarada por usuários e desenvolvedores, ampliando a possibilidade de interação.

Morais (2010, p. 74) aponta que esse formato pode ser compreendido como

A web 2.0 pode ser vista, desse modo, um conjunto de ferramentas aptas a serem apropriadas de modo a favorecer construções coletivas, e facultando a cada usuário liberdade na maneira como interage nesses espaços. Pode ser de modo visto como mais tradicional, navegando entre os conteúdos, ou de forma mais ativa, criando e colaborando para a difusão de conteúdos que venham de alguma forma agregar àqueles sujeitos, bem como orientando suas próprias escolhas.

Nesse contexto, a autora observa a relevância que vem sendo dada por parte dos governos às redes sociais e aponta, a partir de Chang e Kannan (2008, p. 75), alguns aspectos desse uso, a saber:

[...] esse posicionamento governamental pode ser posto em prática baseado em três formas de uso distintas: foco na comunicação com a sociedade, no sentido de divulgar as ações governamentais; foco na interatividade, buscando um feedba$c k$ dos cidadãos sobre as políticas, serviços e ações do Governo; foco nos serviços, disponibilizando pela web 2.0 serviços públicos oferecidos por outros canais de relacionamento entre Estado e sociedade, aumentando a confiança dos cidadãos nas relações virtuais com o governo.

Juntamente a essa perspectiva, o Relatório Anual sobre o Jornalismo Americano (Annual Report on American Journalism), de 2012, destaca o crescimento das mídias sociais e seu potencial para notícia ao longo do ano de 2011, assinalando a importância do Facebook e do Twitter como divulgadores de notícias e informações. No caso americano, o Twitter aparece como a mídia social que os jornalistas mais consultam para obter notícias e informações (27\%), enquanto o Facebook tem um percentual menor (13\%) de consulta por esse público, sendo mais utilizado por amigos e parentes (70\%). 
O Relatório demonstra que Facebook e Twitter são na atualidade caminhos para informação, pois ainda que eles não envolvam a totalidade da população, ${ }^{9}$ aqueles que usam essas mídias o fazem, pois essa é uma nova forma de acessar a notícia e a informação. Isso demonstra que as mídias sociais são padrões adicionais, diferenciando-se da perspectiva tradicional da comunicação.

Essas perspectivas que assinalam essas mídias se apresentam como formas de comunicação nas quais a Administração Púbica pode se aproximar dos cidadãos, divulgar sua ação e construir um espaço que podemos denominar de discussão pública (espaço público). Ainda que essas ferramentas não se proponham à dimensão decisória da política, elas contêm elementos que podem ressignificar esse espaço, ampliando a interação sobre temas de interesse da sociedade.

Assim, pode-se afirmar que, do ponto de vista analítico, a compreensão do uso que a Administração Pública faz desses espaços possibilita identificar em que medida eles são capazes de fortalecer uma cultura cívica, capaz de promover discussões em torno de questões importantes que atravessam a sociedade brasileira.

A noção de espaço público a ser retomada refere-se àquela proposta por Habermas, cuja perspectiva é a de que a democracia, nesse caso, é constituída a partir de publicização do conflito e de reconhecimento de diferentes posições, as quais na arena pública possibilitam um tipo de articulação em torno do interesse público, quepode levar ao consenso e a construção de novas regras e visões em torno de res pública. Para encerrar, pode-se perguntar: serão as mídias sociais capazes de promover a construção de uma vontade geral?

\section{CONSIDERAÇÕES FINAIS: DESAFIOS PARA ADMINISTRAÇÃO PÚBLICA}

Esse texto norteou-se pela seguinte questão central: em que medida as transformações na forma de construção da democracia ampliam o controle do cidadão e possibilitam a transparência? Tratou-se de uma refle-

9 Aqui cabe um debate importante sobre a perspectiva de acesso às tecnologias da informação e aos requisitos (alfabetização, domínio de habilidades) necessários ao seu uso. Sobre isso ver Comitê Gestor da Internet no Brasil (2012) e Morais (2010). 
xão analítica baseada em conceitos e posições destacadas na literatura. Assim, partiu-se de uma discussão proposta por Rousseau acerca da democracia direta, desenvolvendo elementos que denotam o crescimento das mídias sociais no contexto atual e problematizam aspectos relativos à democracia, transparência e participação.

Preliminarmente, uma resposta provisória à questão levantada é que as mídias não podem ser tratadas como a grande descoberta do século. Elas têm um papel importante na construção de uma esfera pública com mais informação para o cidadão e como espaço de aprofundamento de discussões. Nesse aspecto, um dos primeiros resultados da pesquisa mencionada acima mostra que muitos posts colocados no perfil da Secretaria Especial de Igualdade Racial (Seppir) demonstram abertura para abordar a dimensão do racismo e das recentes políticas governamentais para a promoção da igualdade racial. ${ }^{\perp \circ}$

Como desafio para essa questão, pode-se afirmar que o papel da Administração Pública ao divulgar suas informações deve ir além de uma estratégia para a sua promoção, mas deve considerar a perspectiva que as redes sociais colocam para o fortalecimento desse espaço como um espaço de debate, que nas democracias modernas caracterizam-se não somente pelo resultado, mas, essencialmente pela forma como esse resultado é construído, revisitando, dessa forma, algumas das promessas não cumpridas da democracia.

\section{REFERÊNCIAS}

ACIOLI, S. Redes sociais e teoria social: revendo os fundamentos do conceito. Informação e Informação. Londrina, v. 12, n. esp., p. 8-19, 2007. Disponível em: <http://www.uel.br/revistas/uel/index.php/informacao/ article/view/1784/1520>. Acesso em: 15 jul. 2011.

ARENDT, H. A condição humana. Rio de Janeiro: Forense Universitária, 1993 .

BELO HORIZONTE (MG). Prefeitura. OP Digital 2008. Disponível em: $<$ http://opdigital.pbh.gov.br/>. Acesso em: 1 mar. 2013.

10 Informação colhida em entrevista realizada em fevereiro/2013 com a Coordenadora de Comunicação da Seppir. 
BOBBIO, N. O futuro da democracia: uma defesa das regras do jogo. 2. ed. Rio de Janeiro: Paz e Terra, I986.

BRASIL. Congresso Nacional. Câmara dos Deputados. E-democracia: participação virtual, cidadania real. Disponível em: $<$ http://edemocracia. camara.gov.br/>. Acesso em: 01 mar. 2013.

CASTELLS, Manuel. A sociedade em rede. São Paulo: Paz e Terra, I999. (A era da informacão: economia, sociedade e cultura; I).

CASTELLS, M. Um Estado destituído de poder? In: CASTELLS, M. O poder da identidade. São Paulo: Paz e Terra, 1999. Cap. 5, p. 319. (A era da informação: economia, sociedade e cultura; 2).

COMITÊ GESTOR DA INTERNET NO BRASIL. Pesquisa sobre o uso das tecnologias de informação e comunicação no Brasil: TIC domicílios e TIC empresas. São Paulo: Comitê Gestor da Internet no Brasil, 2012. Disponível em: <http://op.ceptro.br/cgi-bin/cetic/tic-domicilios-eempresas-2011.pdf>. Acesso em: 20 mar. 2013.

DAHLBERG, L. The Corporate Colonization of Online Attention and the Marginalization of Critical Communication? Journal of Communication Inquiry, v. 29, n. 2, p. 160-180, Apr. 2005.

DI MAGGIO, P. L. et al. Social implications of the Internet. Annual Review of Sociology, v. 27, p. 307-336, Aug. 2001.

DINIZ, E.; RIBEIRO, M. M.; PRADO, O. Governo eletrônico e transparência: olhar crítico sobre os portais do governo federal brasileiro. In: PINHO, J. A. G. de. (Org.). Estado, sociedade e interações digitais: expectativas democráticas. Salvador: Edufba, 2012.

ECHAVARRÍA, C. El Camino de la democracia digital: panorama em clave deliberativa de los sítios web desarrollados por los municípios cordobeses. In: PINHO, J. A. G. de. (Org.). Estado, sociedade e interações digitais: expectativas democráticas. Salvador: Edufba, 2012.

FRASER, N. Rethinking the Public Sphere: A Contribuition to the Critique of Actually Existing Democracy. In: BRUCE, R (Org.).

The Phantom Public Sphere. Mineápolis: University of Minnesota Press, 1993.

HABERMAS, J. A nova intransparência. Novos Estudos CEBRAP, São Paulo, n. 18, 1987. 
HAMLETT, P. W. Technology Theory and Deliberative Democracy. Science, Technology \& Human Values, v. 28, n. 1, p. 112-140, Jan. 2003.

HEEKS, R.B. Information systems and public sector accountability. Manchester, UK: Institute for Development Policy and Management, 1998. (Working Paper Series; n. 1) Disponível em: http:www.sed. manchester.ac.uk/idpm/reasearch/publications/wp/igoverment/igov_ wpor.htm>. Acesso em: 28 fev. 2013.

JORDAN, T. Language and Libertarianism: The Politics of Cyberculture and the Culture of Cyberpolitics. Sociological Review, v. 49, n. 1, 2001, p. 1-17.

MORAIS, K. S. Mídias Sociais e a Participação Política em Ambiente Digital no Brasil: estudos de caso no governo federal. 2010. Dissertação (Mestre em Administração) - Programa de Pós-Graduação em Administração, Escola de Administração, Universidade Federal da Bahia, Salvador, 2010.

MOSCO, V.; FOSTER, D. Cyberspace and the End of Politics. Journal of Communication Inquiry, v. 25, n. 3, 2001, p. 218-236.

PEW RESEARCH CENTER. The State of News Midias: An Annual Report on American Journalism. 2013. Disponível em http://www. stateofthemedia.org/files/2013/o8/SOTNM-low-rez-pdf.pdf. Acesso em: 10 nov. 2015 .

RIO GRANDE DO SUL. Gabinete Digital. O que é? Disponível em: <http://gabinetedigital.rs.gov.br/\#sobre>. Acesso em: 1 mar. 2013.

ROUSSEAU, J. J. O Contrato social e outros escritos. 4. ed. São Paulo: Cultrix, 1973.

SAMPAIO, R.; MAIA, R.; MARQUES, F. Participação e deliberação na internet: um estudo de caso do Orçamento Participativo Digital de Belo Horizonte. Opinião Pública, Campinas, v. 16, n. 2, p. 446-477, nov. 2010. 